\title{
LONG-TERM EFFECTS OF FINASTERIDE ON PROSTATE TISSUE COMPOSITION
}

\author{
LEONARD S. MARKS, ALAN W. PARTIN, FREDERICK J. DOREY, GLENN J. GORMLEY, \\ JONATHAN I. EPSTEIN, JOEL B. GARRIS, MARIA LUZ MACAIRAN, ERLINDA D. SHERY, \\ PAUL BRYAN SANTOS, ELIZABETH STONER, AND JEAN B. DEKERNION
}

\begin{abstract}
Objectives. To determine the long-term effects of finasteride treatment on prostate tissue composition; to relate these effects to clinical outcomes; and to test the hypothesis that finasteride exerts a selective or preferential action on the transition zone.

Methods. Nineteen men with symptomatic benign prostatic hyperplasia (BPH) who completed a 6-month double-blind trial of finasteride were enrolled in a 24-month open-label extension study of drug responders. Magnetic resonance imaging and prostate biopsy for morphometric analysis were performed together 70 times: at baseline ( $n=19$ ), after treatment periods of intermediate duration ( 6 to 18 months, $n=32$ ), and after long-term drug treatment ( 24 to 30 months, $n=19$ ). At baseline, prostate volume averaged $51 \mathrm{cc}$, of which $57 \%$ was transition zone.

Results. Decreases in symptom score, dihydrotestosterone and prostate-specific antigen levels, and prostate volume occurred at 6 months $(P<0.01)$, stabilized, and were maintained without further long-term decreases. Prostate epithelium contracted progressively from baseline (19.2\% tissue composition; 6.0-cc volume; 3.2 stroma/epithelial ratio) to intermediate $(12.5 \%, 3.3 \mathrm{cc}$, and 5.6, respectively) to long-term treatment $(6.4 \%, 2.0 \mathrm{cc}$, and 17.4 , respectively, $P<0.01$ for all). Percent epithelial contraction was similar in the peripheral and transition zones $(P=\mathrm{NS})$. The transition zone remained a relatively constant proportion (53\% to $58 \%$ ) of whole-prostate volume from baseline to long-term observation.

Conclusions. Long-term finasteride treatment ( 24 to 30 months) results in a marked involution of the prostate epithelium, which continues to progress for many months after clinical effects stabilize. The effect on the epithelium is similar in the peripheral and transition zones for both morphometric and volumetric changes. Progressive contraction of the prostate epithelium appears to constitute the underlying mechanism for sustained action of finasteride. UROLOGY 53: 574-580, 1999. (c) 1999, Elsevier Science Inc. All rights reserved.
\end{abstract}

L ong-term clinical effects of finasteride in men with symptomatic benign prostatic hyperplasia (BPH) have been thoroughly characterized. ${ }^{1-5}$ For

G.J. Gormley and E. Stoner are employees of Merck, Inc.

This study was supported in part by unrestricted educational grants from Merck \& Co., the Urological Sciences Research Foundation, and the American Foundation for Urological Diseases.

From the Departments of Urology and Biostatistics, University of California, Los Angeles School of Medicine, Los Angeles, California; Brady Urological Institute, Johns Hopkins University School of Medicine, Baltimore, Maryland; Merck Research Laboratories, Rahway, New Jersey; and Urological Sciences Research Foundation and Radiology Department, Brotman Medical Center, Culver City, California

Reprint requests: Leonard S. Marks, M.D., Urological Sciences Research Foundation, Culver Medical Plaza, 3831 Hughes Avenue, Suite 700, Culver City, CA 90232

Submitted: August 18, 1998, accepted: September 28, 1998 example, in the Proscar Long-Term Efficacy and Safety (PLES) study, men treated with finasteride for 4 years exhibited a sustained decrease in voiding symptoms, prostate volume, and serum prostate-specific antigen (PSA) levels and a sustained increase in urinary flow rate compared with placebo-treated control subjects. ${ }^{1}$ Moreover, the treated men also experienced a $55 \%$ reduction in risk of surgical intervention and a 57\% reduction in risk of acute urinary retention compared with the untreated men. ${ }^{1}$

However, prostatic tissue changes, which may explain the clinical effects of finasteride, have only been systematically evaluated for up to 6 months of treatment. ${ }^{6,7}$ Long-term tissue effects might have important implications regarding the mechanism 
41 Men with Symptomatic BPH

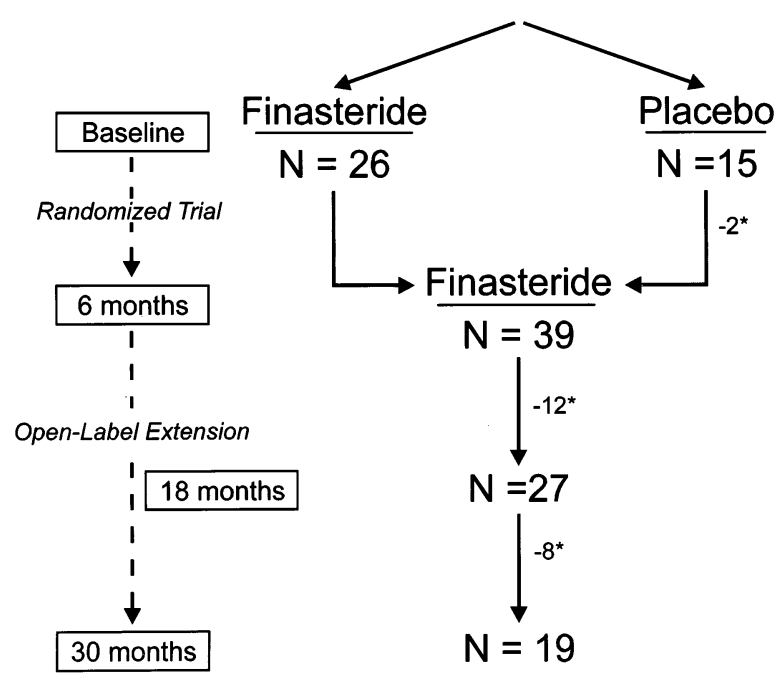

FIGURE 1. Flow chart of study design. Of the original 41 patients, 22 dropped out of the study (asterisks) for the following reasons: invasive prostate cancer in 2 , adverse side effects in 4, lost to follow-up in 4, unrelated death in 2, and lack of efficacy in 10. $\mathrm{BPH}=$ benign prostatic hyperplasia. Results of randomized trial part of study are reported elsewhere. ${ }^{6}$

of action of the drug. Furthermore, finasteridetreated men remain at risk of developing prostate cancer, which requires a biopsy diagnosis; hence, information about finasteride-induced tissue changes in men with BPH (ie, "control" histologic data) would be important in biopsy interpretation. 8,9

Thus, to help clarify the long-term histologic effects of finasteride, we quantified prostatic tissue components in serial biopsies of men with BPH before, during, and after 24 to 30 months of finasteride treatment. By analyzing inner and outer gland tissue separately, the present study was also designed to test the "transition zone hypothesis," a concept that finasteride may exert a selective or preferential effect on the inner prostate. ${ }^{6,10,11}$

\section{MATERIAL AND METHODS}

\section{STUDY DESIGN}

The study design is presented schematically in Figure 1. The study was an open-label extension of a 6-month doubleblind trial that was previously published. ${ }^{6}$ In the original study, men with symptomatic BPH were randomized to receive placebo $(n=15)$ or finasteride $(n=26)$ for 6 months. On completion of the 6-month placebo-controlled period, all participants were invited to enroll in a long-term open-label extension study of active finasteride therapy.

Of the original group of $41 \mathrm{men}, 39$ completed the 6-month double-blind study. Twenty-seven men completed a 1-year extension, and 19 men - the present study group — completed a 2-year extension. Of the 19 long-term participants, 6 were originally randomized to receive placebo for 6 months; as their baseline for the present report, we used those data obtained
TABLE I. Demographic characteristics of 19 patients at baseline

\begin{tabular}{lc}
\hline Age (yr) & $62.8 \pm 6.7$ \\
Race & 12 \\
$\quad$ White & 5 \\
$\quad$ African-American & 2 \\
$\quad$ Asian & $15.9 \pm 6.7$ \\
IPSS & $13.2 \pm 4.1$ \\
Max uroflow (cc/s) & $3.0 \pm 2.5$ \\
Serum PSA (ng/mL) & $45.4 \pm 21.0$ \\
Serum DHT (ng/dL) & \\
Prostate volume on MRI (cc) & $51 \pm 28$ \\
$\quad$ Whole gland & $29 \pm 20$ \\
$\quad$ Transition zone & \\
Prostatic tissue composition (\%) & $19.2 \pm 7.7$ \\
$\quad$ Epithelium & $31.7 \pm 6.4$ \\
$\quad$ Lumen & $49.2 \pm 9.8$
\end{tabular}

KEY: DHT = dihydrotestosterone $;$ IPSS = International Prostate Symptom Score Max $=$ maximal; $M R I=$ magnetic resonance imaging; $P S A=$ prostate-specific antigen.

Data presented are mean value $\pm S D$ or number of patients.

just before starting active drug. Thus, 6 men were receiving finasteride for 24 months, and 13 were receiving finasteride for 30 months. Study dropouts are explained in Figure 1.

\section{PATIENTS}

Baseline demographic data for the 19 men reported herein are presented in Table I. At entry, the patients were middleaged, with chronic, uncomplicated prostatism, exhibiting some degree of prostate enlargement on rectal examination; an International Prostate Symptom Score (IPSS) of 9 or more; and a serum PSA level less than $10 \mathrm{ng} / \mathrm{mL}$. Exclusion criteria included concurrent use of alpha-adrenergic blocking agents; history of neurogenic bladder or urethral stricture; urinary infection; or any previous invasive treatment for BPH. At the outset of the extension, a consent form, approved by the Western Institutional Review Board, Portland, Oregon, was signed by each participant.

The 19 men were thus highly selected, that is, men who were satisfied with results of treatment for 24 to 30 months, who had no intolerable side effects of finasteride, who developed no cancer or BPH complications mandating surgical intervention, and who remained evaluable throughout the repetitive magnetic resonance imaging (MRI) and biopsy components of the study.

\section{Outcome MeAsures}

At baseline and at 6, 18, and 30 months, participants had the following tests: voiding symptom score (IPSS); maximal uroflow; serum dihydrotestosterone (DHT) and PSA levels; prostate MRI for whole and zonal volumetrics; and transrectal ultrasound-guided sextant biopsy (18 gauge) for routine histologic evaluation and quantitative image analysis or morphometric analysis. Morphometric analysis was performed in a blinded manner by a study author (A.W.P.) using a technique of computer-assisted color image analysis. ${ }^{6}$ The deep portion of each biopsy core was stained with India ink to identify the transition zone, a method validated in a separate study reported elsewhere. ${ }^{6}$ Morphometric analysis was performed for the transition and peripheral zones separately, as well as for the entire core, to determine percent epithelium, percent lu- 
TABLE II. Clinical and chemical changes during finasteride treatment

\begin{tabular}{|c|c|c|c|}
\hline & $\begin{array}{c}\text { Baseline } \\
\text { (mean } \pm \text { SD) }\end{array}$ & $\begin{array}{l}\text { Intermediate } \\
\text { (mean } \pm \text { SD) }\end{array}$ & $\begin{array}{c}\text { Long-Term } \\
(\text { mean } \pm \text { SD) }\end{array}$ \\
\hline IPSS & $15.9 \pm 6.7$ & $9.2 \pm 5.8^{*}$ & $6.8 \pm 4.1^{*}$ \\
\hline $\begin{array}{l}\text { Max uroflow } \\
\text { (cc/s) }\end{array}$ & $13.2 \pm 4.1$ & $16.5 \pm 7.4$ & $14.3 \pm 4.5$ \\
\hline PSA (ng/mL) & $3.0 \pm 2.5$ & $1.5 \pm 1.3^{*}$ & $1.2 \pm 1.0^{*}$ \\
\hline DHT (ng/dL) & $45.2 \pm 21.0$ & $11.4 \pm 6.2^{*}$ & $9.5 \pm 3.8^{*}$ \\
\hline \multicolumn{4}{|c|}{$\begin{array}{l}\text { KEY: Baseline }=19 \text { measurements; Intermediate }=32 \text { measurements at } 6 \text { to } 18 \\
\text { months; Long-Term }=19 \text { measurements at } 24 \text { to } 30 \text { months; other abbreviations as } \\
\text { in Table I. } \\
\text { * Statistically significant change from baseline }(\mathrm{P}<0.01) \text {; no changes between } \\
\text { intermediate and long-term values are statistically significant. }\end{array}$} \\
\hline
\end{tabular}

men, and percent stroma, as previously described. ${ }^{6}$ Tissue volumes were calculated by multiplying the morphometrically determined percent tissue composition times the MRI-determined volume of the prostate or one of its zones.

Independent observers, working without knowledge of the other results, obtained the clinical (L.S.M.), volumetric (J.B.G.), histologic (J.I.E.), and morphometric (A.W.P.) data. Methodology for all outcome measures was constant from baseline through the 30-month end point. Detailed methodology of outcome measures used in the present report has been published previously. ${ }^{6}$

\section{Data Processing and Statistical Analysis}

Because of the crossover study design, which limited the number of patient entries at each point, data are reported and analyzed only at baseline $(n=19)$ and two end points ("intermediate" and "long term"). The intermediate end point includes measurements made after 6 months $(n=13)$, after 12 months $(n=6)$, and after 18 months of finasteride treatment $(n=13)$. The long-term end point includes measurements made after $24(n=6)$ or 30 months of treatment $(n=13)$. Thus, 19 data points are averaged for each outcome measure at baseline; 32 at the intermediate point; and 19 at long term, for a total of 70 end-point assessments. In 5 patients MRI data were not available at baseline, and for these patients the MRI volumes were imputed from the ultrasound measurements, according to a regression validated elsewhere. ${ }^{6}$ A detailed analysis of the 6-month placebo-controlled data $(\mathrm{n}=39)$ was reported previously. ${ }^{6}$

All data were entered into an IBM-compatible personal computer through Excel spreadsheets and analyzed using the Stata statistical package (Stata Corp, College Station, Tex). The paired $t$ test was used when evaluating test results before versus after treatment. Repeated-measures analysis of variance was used when evaluating serial changes. The relation between continuous variables was tested using the nonparametric Kendall tau correlation. Multivariate analysis was performed using linear regression. Statistical significance was defined a priori as $P<0.05$.

\section{RESULTS}

Demographic characteristics of the study group at baseline are shown in Table I. In general, the patients were middle-aged men with chronic, uncomplicated, moderate prostatism, who continued to respond favorably to finasteride during 24 to 30 months of treatment.

Symptom score and serum levels of PSA and

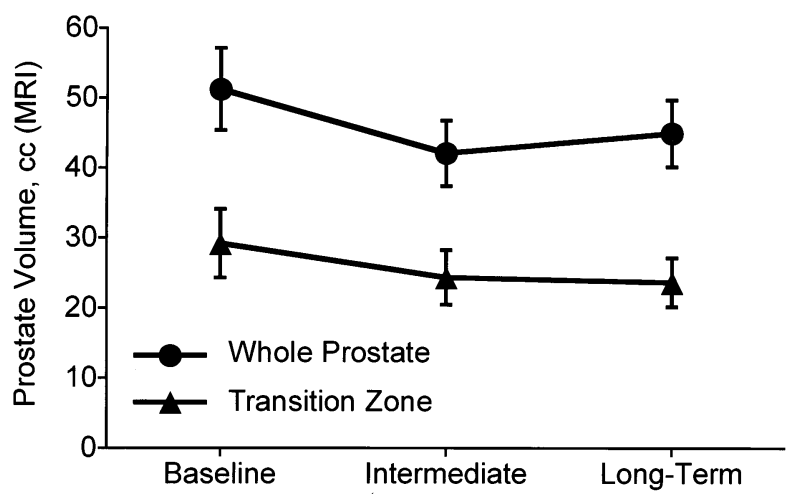

FIGURE 2. Prostate volume changes, determined by magnetic resonance imaging (MRI), during long-term finasteride treatment. Transition zone volume is determined separately and is seen to approximately parallel changes seen in whole prostate. Changes at the intermediate point are significantly different from baseline values ( $\mathrm{P}<0.01)$. Changes at the long-term point remain significantly different from baseline values ( $\mathrm{P}$ $<0.05)$ but not from intermediate values.

DHT all decreased during the study (Table II). The decrease from baseline was statistically significant at the intermediate term $(P<0.01)$ and was maintained thereafter. For these three measures, a slight further decrease observed at the long-term point was not significantly different from that seen at the intermediate point $(P=N S)$. Maximal urinary flow rate increased during the treatment, but the change was not statistically significant in this group of 19 patients.

In Figure 2, prostate volume changes are depicted. Whole-prostate volume decreased from an average of $51.3 \mathrm{cc}$ at baseline to $42.2 \mathrm{cc}$ at the intermediate point, a $17.8 \%$ decrease $(P<0.01)$. At the long-term point, the decrease remained statistically significant from baseline $(P<0.05)$ but not from the intermediate point ( $P=N S)$. Transition zone volume at baseline averaged $29.2 \mathrm{cc}$ and decreased to $24.4 \mathrm{cc}$ at the intermediate point, a $16.4 \%$ decrease $(P<0.05)$, which did not change significantly thereafter. The transition zone remained relatively constant in its contribution to whole-gland volume, averaging 57\% of wholegland volume at baseline, $58 \%$ at the intermediate point, and 53\% at the long-term point.

The effect of finasteride on three different measures of prostate epithelium-percent, volume, and stroma/epithelial ratio-is shown in Table III. At baseline, the average prostate gland was morphometrically determined to be $19.2 \%$ epithelial and contained a volume of $6.0 \mathrm{cc}$ of epithelium; the stroma/epithelial ratio (percent stroma/percent epithelium) was 3.2. All three measures of prostate epithelium are seen to change progressively from baseline to the intermediate point and even further from the intermediate to the long-term point. Each 
TABLE III. Changes in prostate epithelium during finasteride treatment

\begin{tabular}{lrrr}
\hline & $\begin{array}{c}\text { Baseline } \\
\text { (mean } \pm \text { SD) }\end{array}$ & $\begin{array}{c}\text { Intermediate } \\
\text { (mean } \pm \text { SD) }\end{array}$ & $\begin{array}{c}\text { Long-Term } \\
\text { (mean } \pm \text { SD) }\end{array}$ \\
\hline \% Epithelium & $19.2 \pm 7.7$ & $12.5 \pm 5.5^{*}$ & $6.4 \pm 4.0^{*}$ \\
$\begin{array}{l}\text { Epithelial volume } \\
\text { (cc) }\end{array}$ & $6.0 \pm 2.8$ & $3.3 \pm 1.6^{*}$ & $2.0 \pm 1.6^{*}$ \\
Stroma/epithelial & $3.2 \pm 1.8$ & $5.6 \pm 3.1^{*}$ & $17.4 \pm 13.4^{*}$ \\
$\quad$ ratio \\
Key: Abbreviations as in Table II. \\
* Statistically significant change from preceding value (P <0.01). \\
\hline
\end{tabular}

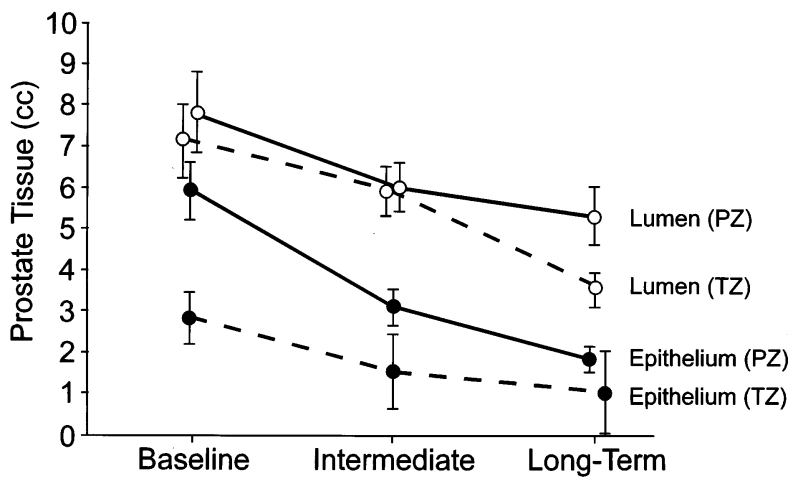

FIGURE 3. Volumetric decreases in lumen and epithelium for peripheral (PZ) and transition zone (TZ) tissues during long-term finasteride treatment. Stroma volume also decreases (not shown in figure), but in terms of percent of tissue composition, stroma increases. All changes are statistically significant ( $\mathrm{P}<0.01)$, except for the long-term change in peripheral zone lumen.

shift is significantly different from the preceding value $(P<0.001)$, with the percent epithelium and epithelial volume finally reaching a level of $6.4 \%$ and $2.0 \mathrm{cc}$, respectively, each approximately one-third the baseline value. Conversely, the stro$\mathrm{ma}$ /epithelial ratio increased progressively and dramatically during finasteride administration, from 3.2 at baseline to 5.6 at the intermediate point to 17.4 at the long-term point $(P<0.001)$.

The effect of finasteride on tissue volumes of the separate zones of the prostate is shown in Figure 3. At baseline, the average peripheral zone contained $5.9 \mathrm{cc}$ of epithelium (percent times volume) and $7.8 \mathrm{cc}$ of lumen. The average transition zone contained $2.8 \mathrm{cc}$ of epithelium and $7.1 \mathrm{cc}$ of lumen. During treatment, epithelial and luminal tissues both contracted progressively from baseline to intermediate to long-term $(P<0.01)$; the effect is statistically significant in both the peripheral and transition zone $(P<0.01)$. Peripheral zone epithelium demonstrated a $71 \%$ decrease, from an average of $5.9 \mathrm{cc}$ before treatment to $1.8 \mathrm{cc}$ at longterm follow-up. In the transition zone, the epithelial volume decreased $64 \%$, from $2.8 \mathrm{cc}$ at baseline to $1.0 \mathrm{cc}$ at long-term follow-up. Luminal decreases from baseline to long-term follow-up were $32 \%$ for the transition zone and $51 \%$ for the peripheral zone $(P<0.01)$. Stroma volumes (not shown) decreased absolutely but increased as a percent of the whole prostate.

The patient-to-patient and temporal variability of epithelial response is illustrated in Figure 4. In Figure $4 \mathrm{~A}$, the most typical response pattern, the epithelium was suppressed in a progressive manner, that is, lower at the intermediate point than at baseline and lower at the long-term point than at the intermediate point $(n=7)$. In Figure 4B, there was epithelial suppression at the intermediate point, with little additional change at the longterm point $(n=5)$. In Figure 4C, epithelial suppression occurred as a delayed response and was notable only after the intermediate point $(n=5)$. In Figure 4D, no change was observed $(n=2)$. Ultimately, reduction in epithelial composition by $50 \%$ or more (baseline versus long-term end point) was found in 17 of the 19 patients.

In a multivariate regression analysis, we found that at baseline, prostate volume was directly correlated with serum PSA level and both percent and volume of epithelium, that is, the large prostate glands were associated with high serum PSA levels and with both a relative and an absolute epithelial richness. Long-term change in prostate volume was directly correlated with baseline prostate volume, serum PSA level, and both percent and volume of epithelium. For all these associations, correlation coefficients ranged between 0.39 and 0.83 $(P<0.05)$. When transition zone measures were substituted for whole-prostate measures in this analysis, the correlations were similar or weaker than when whole prostate was used. In other words, baseline characteristics of the transition zone were no better an index of finasteride response than those of the whole prostate.

\section{COMMENT}

Huggins and Stevens ${ }^{12}$ were among the first to quantify the effect of androgen deprivation (AD) on human prostatic tissue. Using an ocular micrometer, these investigators found that prostatic epithelial cells shrink and acini decrease in size after castration therapy for symptomatic BPH. Herein we confirm and expand those observations from 60 years ago, using contemporary morphometric analysis to study finasteride treatment, which allows prostatic $\mathrm{AD}$ without the systemic side effects of castration. ${ }^{13}$ In Figure 5, landmark photomicrographs from the work of Huggins and Stevens ${ }^{12}$ are shown alongside comparison photomicrographs from the present work.

Using a variety of treatments and methods, others have subsequently attempted to quantify the 

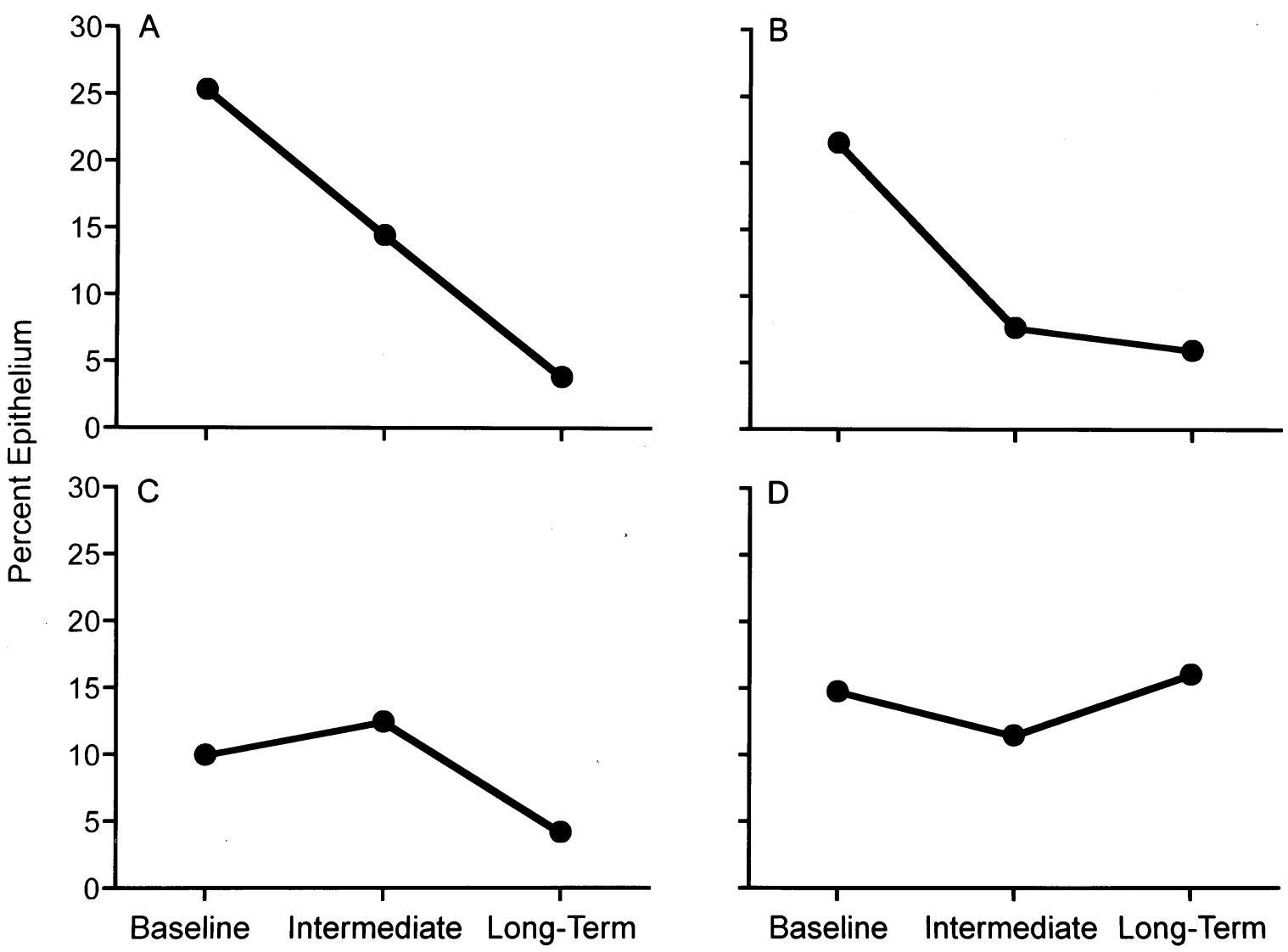

FIGURE 4. Variability in epithelial response during long-term finasteride treatment. Examples of four types of responses are shown: (A) progressive contraction $(n=7)$; $(B)$ early contraction $(n=5)$; (C) delayed contraction $(n=5)$; (D) no effect $(n=2)$.

effects of $\mathrm{AD}$ on human $\mathrm{BPH}$ histologic features. ${ }^{6,14-20}$ The prostatic effects of AD have also been demonstrated in rats $^{21}$ and dogs ${ }^{22}$ treated with finasteride. Consistently, the major effect appears to be involution of the epithelium. However, using conventional histologic evaluation, the characteristics of epithelial atrophy are spotty and nonspecific. $^{23}$ Thus, contemporary morphometric analysis, ${ }^{24-26}$ used here to measure field change rather than individual cells, has provided a degree of quantitation not available with other methods of tissue analysis. The validity of using biopsy specimens to index prostatic tissue composition has been demonstrated previously. ${ }^{27}$

The clinical, chemical, and volumetric observations made in the present group of long-term finasteride responders are consistent with previous reports. ${ }^{1-5}$ After 6 months of treatment, prostate volume decreases by approximately $18 \%$ to $20 \%$; serum levels of DHT and PSA decrease by approximately $70 \%$ and $50 \%$, respectively; voiding symptoms and flow rates are improved; and the new levels are maintained for years thereafter. Thus, the present group of patients, although highly selected (see Material and Methods, Patients), appears to be representative of the thousands of men studied in other clinical trials. Epithelial contraction, which we found to be statistically significant at 6 months, ${ }^{6}$ clearly continues further to the intermediate observation and still further to long-term follow-up (24 to 30 months). Thus, the tissue changes induced in the prostatic gland of finasteride responders are dramatic, enduring, and, in fact, progressive during several years of treatment. Progressive epithelial atrophy appears to be a basic mechanism of action of the drug and may explain the important benefits- $55 \%$ to $57 \%$ risk reduction for operation or acute urinary retention-seen in men treated with long-term finasteride therapy. ${ }^{1}$

Indirect evidence, based on serum PSA levels, indicates that finasteride may exert a preferential effect on the transition zone. The transition zone, not the whole prostate, appears to be the major source of PSA in the serum of men with BPH. ${ }^{28-31}$ In men with relatively high serum PSA levels, the response to finasteride is better than in those with low PSA levels. ${ }^{32}$ Furthermore, finasteride treatment results in a reduction of serum PSA levels out of proportion to the reduction of whole-prostate volume, ${ }^{8,13}$ suggesting the possibility of a preferential effect on the transition zone. In more direct studies, Tempany et al., ${ }^{10}$ using MRI volumetrics, 

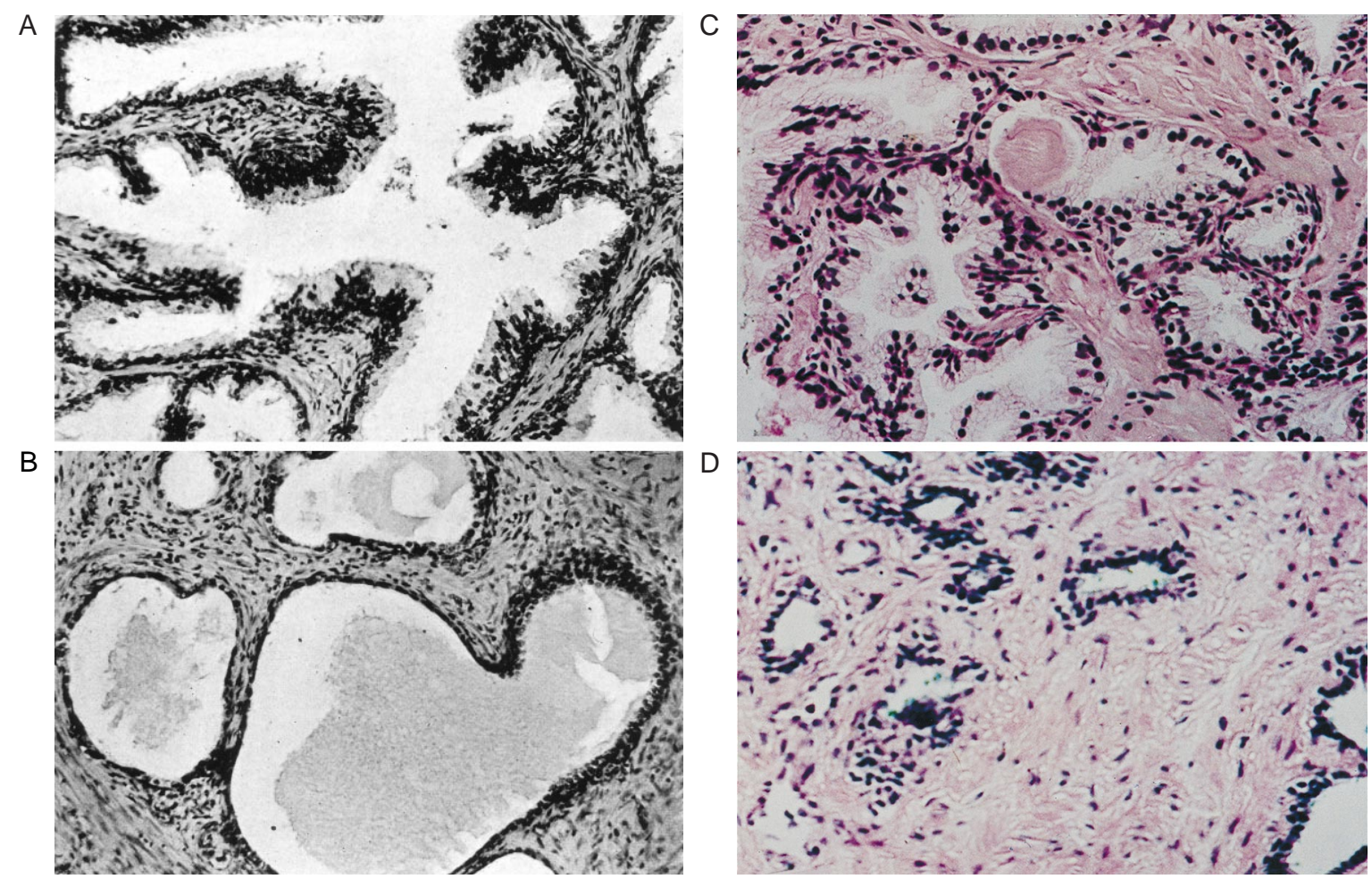

FIGURE 5. (A and B) Photomicrographs of prostatic tissue before (A) and 86 days after (B) castration treatment for benign prostatic hyperplasia. (Original magnification $\times 235$ ). Reprinted, with permission, from Huggins $C$, and Stevens RA: The effect of castration on benign hypertrophy of the prostate in man. J Urol 43: 705-714, 1940. (C and D) Color photomicrographs of prostatic tissue before $(C)$ and after (D) 24 months of finasteride treatment. Enlarged from $\times 100$. Marked flattening of epithelium and decrease in acinar diameter are noted after both treatments.

and Tewari et al., ${ }^{11}$ using transrectal ultrasound, found that finasteride treatment seemed to shrink the transition zone more than the whole prostate. However, neither the study by Tempany et al. ${ }^{10}$ nor that by Tewari et al. ${ }^{11}$ is regarded as conclusive because of limited numbers of patients, only a single evaluation after treatment, large numbers of dropouts, and/or conflicting data.

The present work was designed in part to test the transition zone hypothesis of finasteride action and differs from previous reports in two important ways: (1) MRI and morphometric tissue analysis were used to assess the intact prostate before and serially during long-term finasteride treatment. (2) In addition to whole-gland studies, the peripheral and transition zones of the prostate were evaluated separately. Throughout the present study, the transition zone remained a constant percent of wholeprostate volume, and epithelial suppression was parallel in the transition and peripheral zones. Thus, in contrast to the placebo-controlled results found at 6 months, ${ }^{6}$ we found no evidence for a long-term preferential effect of finasteride on the inner prostate in treatment responders. In the present patients, prostate volume averaged $51 \mathrm{~g}$ at baseline. Results might be different in men with an even larger prostate gland and/or a larger transition zone because response to finasteride is directly correlated with prostate volume. ${ }^{33}$

Substantial variability was seen in the epithelial response to finasteride, both between patients and temporally (Fig. 4). Although 17 of the 19 men ultimately exhibited a dramatic (50\% or more) reduction in epithelial tissue, some men exhibited progressive suppression; others showed a delayed response; and in 2 patients, no change was seen. Whether use of a dual inhibitor of 5-alpha reductase (5-AR) would lead to faster or more uniform epithelial suppression than that seen with finasteride is unknown and would be of interest. ${ }^{34}$

\section{CONCLUSIONS}

Taken altogether, the present data indicate that long-term finasteride treatment (24 to 30 months) results in marked suppression of the prostate epithelium. The effect is proportionately similar in both peripheral and transition zones for both volumetric and morphometric changes. Three different measures of prostate epithelium-percent tissue composition, volume, and stroma/epithelial ratio-all reflected an epithelial involution that continues to progress for many months after clinical changes have stabilized. Progressive contraction of 
the prostate epithelium appears to constitute the underlying mechanism for the sustained action of finasteride.

Acknowledgment. To Emmanuel Abrams, M.D., Department of Pathology, Brotman Medical Center, Culver City, California, for providing invaluable assistance with processing biopsy materials.

\section{REFERENCES}

1. McConnell JD, Bruskewitz R, Walsh P, et al: The effect of finasteride on the risk of acute urinary retention and the need for surgical treatment among men with benign prostatic hyperplasia: Finasteride Long-Term Efficacy and Safety Study Group. N Engl J Med 338: 557-563, 1998.

2. Stoner E: Three-year safety and efficacy data on the use of finasteride in the treatment of benign prostatic hyperplasia. Urology 43: 284-292, 1994.

3. Ekman P: Maximum efficacy of finasteride is obtained within 6 months and maintained over 6 years. Follow-up of the Scandinavian Open-Extension Study. The Scandinavian Finasteride Study Group. Eur Urol 33: 312-317, 1998.

4. Moore E, Bracken B, Bremner W, et al: Proscar: fiveyear experience. Eur Urol 28: 304-309, 1995.

5. Marberger MJ: Long-term effects of finasteride in patients with benign prostatic hyperplasia: a double-blind, placebo-controlled, multicenter study. PROWESS Study Group. Urology 51: 677-686, 1998.

6. Marks LS, Partin AW, Gormley GJ, et al: Prostate tissue composition and response to finasteride in men with symptomatic benign prostatic hyperplasia. J Urol 157: 2171-2178, 1997.

7. Rittmaster RS, Norman RW, Thomas LN, et al: Evidence for atrophy and apoptosis in the prostates of men given finasteride. Clin Endocrinol Metab 81: 814-819, 1996.

8. Guess HA, Heyse JF, Gormley GJ, et al: Effect of finasteride on serum PSA concentration in men with benign prostatic hyperplasia: results from the North American phase III clinical trial. Urol Clin North Am 20: 627-636, 1993.

9. Oesterling JE, Roy J, Agha A, et al and the Finasteride PSA Study Group: Biologic variability of prostate-specific antigen and its usefulness as a marker for prostate cancer: effects of finasteride. Urology 51 (suppl 4A): 58-63, 1998

10. Tempany CMC, Partin AW, Zerhouni EA, et al: The influence of finasteride on the volume of the peripheral and periourethral zones of the prostate in men with benign prostatic hyperplasia. Prostate 22: 39-42, 1993.

11. Tewari A, Shinohara K, and Narayan P: Transition zone volume and transition zone ratio: predictor of uroflow response to finasteride therapy in benign prostatic hyperplasia patients. Urology 45: 258-265, 1995.

12. Huggins C, and Stevens RA: The effect of castration on benign hypertrophy of the prostate in man. J Urol 43: 705714,1940

13. Gormley GJ, Stoner E, Bruskewitz RC, et al: The effect of finasteride in men with benign prostatic hyperplasia. N Engl J Med 327: 1185-1191, 1992.

14. Geller J, Bora R, Roberts T, et al: Treatment of benign prostatic hypertrophy with hydroxyprogesterone caproate. JAMA 193: 115-122, 1965.

15. Scott WW, and Wade JC: Medical treatment of benign nodular prostatic hyperplasia with cyproterone acetate. J Urol 101: 81-85, 1969.

16. Wendel EF, Brannen GE, Putong PB, et al: The effect of orchiectomy and estrogens on benign prostatic hyperplasia. J Urol 108: 116-119, 1972.

17. Peters CA, and Walsh PC: The effect of naferelin acetate, a luteinizing-hormone-releasing hormone agonist, on benign prostatic hyperplasia. N Engl J Med 317: 599-604, 1987.

18. Harada M, Kinoshita Y, and Masatoshi M: Histological evaluation of benign prostatic hyperplasia treated by longterm administration of chlormadinone acetate (CMA). Prostate 25: 147-155, 1994.

19. Montironi R, Valli M, and Fabris G: Treatment of benign prostatic hyperplasia with 5 - $\alpha$-reductase inhibitor: morphological changes in patients who fail to respond. J Clin Pathol 49: 324-328, 1996.

20. Svindland A, Eri LM, and Tveter KJ: Morphometry of benign prostatic hyperplasia during androgen suppressive therapy. Scand J Urol Nephrol 179 (suppl): 113-117, 1996.

21. Laroque PA, Prahalada S, Molon-Noblot S, et al: Quantitative evaluation of glandular and stromal compartments in hyperplastic dog prostates: effect of 5-alpha reductase inhibitors. Prostate 27: 121-128, 1995.

22. Prahalada S, Rhodes L, Grossman SJ, et al: Morphological and hormonal changes in the ventral and dorsolateral prostate lobes of rats treated with finasteride, a 5-alpha reductase inhibitor. Prostate 35: 157-164, 1998.

23. Epstein JI, Marks LS, and Partin AW: Histological changes in benign prostate biopsies following long-term finsteride therapy for benign prostatic hyperplasia. J Urol Pathol (in press).

24. Bartsch G, Muller HR, Oberholzer M, et al: Light microscopic stereologic analysis of the normal prostate and of benign prostatic hyperplasia. J Urol 122: 487-491, 1979.

25. Rohr HP and Bartsch G: Human benign prostatic hyperplasia: a stromal disease? New perspectives by quantitative morphology. Urology 16: 625-633, 1980.

26. Shapiro E, Becich MJ, Hartanto V, et al: The realtive proportion of stromal and epithelial hyperplasia is related to the development of symptomatic benign prostatic hyperplasia. J Urol 147: 1293-1297, 1992.

27. Marks LS, Treiger B, Dorey FJ, et al: Morphometry of the prostate: I. Distribution of tissue components in hyperplastic glands. Urology 44: 486-492, 1994.

28. Lepor H, Wang B, and Shapiro E: Relationship between prostatic epithelial volume and serum PSA levels. Urology 44: 199-205, 1994

29. Kalish J, Cooner WH, and Graham SD: Serum PSA adjusted for volume of transition zone (PSAT) is more accurate than PSA adjusted for total gland volume (PSAD) in detecting adenocarcinoma of prostate. Urology 43: 601-606, 1994.

30. Hammerer PG, McNeal JE, and Stamey TA: Correlation between serum prostate specific antigen levels and the volume of the individual glandular zones of the human prostate. J Urol 153: 111-114, 1995

31. Marks LS, Dorey FJ, Rhodes T, et al: Serum PSA levels after TURP: longitudinal characterization in men with BPH. J Urol 156: 1035-1039, 1996.

32. Waldstreicher J, Roehrborn CG, Boyle P, et al: Baseline serum PSA and prostate volume predict long-term symptomatic response to finasteride: results of a four-year placebocontrolled trial (abstract). J Urol 159(suppl A): 255A, 1998.

33. Boyle P, Gould AL, and Roehrborn CG: Prostate volume predicts outcome of treatment of benign prostatic hyperplasia with finasteride. Urology 48: 398-405, 1996.

34. Bramson HN, Hermann D, Batchelor KW, et al: Unique preclinical characteristics of GG745, a potent dual inhibitor of 5AR. J Pharmacol Exp Ther 282: 1496-1502, 1997. 